\title{
Stress management to reduce prisoner stress levels (Community service training in class I Tanjung Gusta prison, Medan)
}

\author{
Rodiatul Hasanah Siregar ${ }^{1 *}$, Hasnida ${ }^{1}$, Raras Sutatminingsih ${ }^{1}$, Juliana Irmayanti Saragih ${ }^{1}$ \\ Arliza Juariani Lubis ${ }^{1}$ \\ ${ }^{1}$ Faculty of Psychology, University of North \\ Sumatera Email*: rodhia.siregar@gmail.com
}

\begin{abstract}
Penitentiary (prison) is a place where prisoners' room is limited and they are isolated from the community. Prison conditions in Indonesia that are overcapacity now are also conditions that are not ideal for the lives of prisoners. The room must be filled with many people, simple and less varied food, and strict prison rules are stressors that cause prisoners to experience stress. Sarafino (2011) defines stress as a condition where transactions between individuals and the environment lead to a perceived gap between the physical or psychological demands of a situation with the resources of one's biological, psychological, and social systems. The condition of prisoners who experience stress causes them to get angry easily and even behave aggressively which makes the prison atmosphere more uncomfortable. Therefore prisoners need to be helped to manage their stress through Stress Management Training. Stress Management Training given to male prisoners in class I Tanjung Gusta Medan shows the results that stress management techniques taught and applied by prisoners in daily life can reduce the level of stress they experience. Furthermore, by applying stress management techniques routinely, they are expected to be able to manage their stress better so they can live comfortably while serving their sentences in prison.
\end{abstract}

Keywords: Stress, Stress Management

\begin{abstract}
Abstrak
Lembaga Pemasyarakatan (lapas) merupakan sebuah tempat dimana ruang gerak narapidana dibatasi dan mereka terisolasi dari masyarakat. Kondisi lapas di Indonesia yang overcapacity saat ini juga merupakan kondisi yang tidak ideal untuk kehidupan para narapidana. Ruangan yang harus diisi banyak orang, makanan yang sederhana dan kurang bervariasi, serta aturan lapas yang ketat merupakan stressor yang menyebabkan para narapidana mengalami stres. Sarafino (2011) mendefinisikan stres sebagai kondisi dimana transaksi antara individu dengan lingkungan mengarah pada kesenjangan yang dirasakan antara tuntutan fisik atau psikologis dari suatu situasi dengan sumber daya sistem biologis, psikologis, dan sosial seseorang. Kondisi narapidana yang mengalami stres menyebabkan mereka mudah marah bahkan berperilaku agresif yang membuat suasana lapas semakin tidak nyaman. Oleh karena itu para narapidana perlu dibantu mengelola stres mereka melalui Pelatihan Manajemen Stres. Pelatihan Manajemen Stres yang diberikan kepada narapidana Pria kelas I Tanjung Gusta Medan menunjukkan hasil bahwa teknik-teknik manajemen stres yang diajarkan dan diterapkan oleh para narapidana dalam kehidupan sehari-hari dapat menurunkan tingkat stres yang mereka alami. Lebih lanjut, dengan menerapkan teknik-teknik manajemen stres secara rutin diharapkan mereka dapat mengelola stres mereka dengan lebih baik sehingga mereka dapat hidup nyaman selama menjalani masa hukuman di lapas.
\end{abstract}

Kata kunci : Stres, Manajemen Stres

\section{PENDAHULUAN}

Hidup di penjara bukanlah merupakan kehidupan yang menyenangkan. Pidana penjara pada prinsipnya bersifat perampasan kemerdekaan pribadi terpidana karena penempatannya dalam bilik- bilik penjara. Menurut Mulyadi (2015) kehilangan-kehilangan itu antara lain adalah kehilangan kebebasan (lose of autonomy), hilangnya pelayanan (lose of good and service), hilangnya rasa aman (lose of security), dan hilangnya hubungan heteroseksual (lose of heterosexual). Selain itu kondisi di lapas juga dapat menjadi stressor tersendiri bagi para 
narapidana. Data Kementerian Hukum dan Hak Asasi Manusia (Kemenkumham) menunjukkan bahwa lembaga pemasyarakatan

(lapas) di Indonesia mengalami over kapasitas di tahun 2018. Hal itu merujuk dari total tahanan dan narapidana mencapai 255 ribu (Okezone.com, 2018).

Perbedaan kehidupan sebelum dengan sesudah masuk lapas yang jauh berbeda membuat narapidana rentan mengalami stres. Sarafino (2011) mendefinisikan stres sebagai kondisi dimana transaksi antara individu dengan lingkungan mengarah pada kesenjangan yang dirasakan antara tuntutan fisik atau psikologis dari suatu situasi dengan sumber daya sistem biologis, psikologis, dan sosial seseorang. Taylor (2015) menggambarkan stres sebagai pengalaman emosi negatif yang disertai dengan perubahan reaksi biokimia, fisiologis, kognitif, dan perilaku yang terprediksi yang ditujukan baik untuk mengubah peristiwa stres atau mengakomodasi efeknya. Menurut Lazarus (1984) apabila stres tidak ditangani dan dikelola dengan baik, maka akan memberikan efek jangka lama yang berdampak pada timbulnya penyakit, gangguan somatik, gangguan kesehatan, dan gangguan fungsional. Sayangnya, para narapidana sedikit menggunakan koping stres yang adaptif (Gullone, dkk, 2000). Mengingat jumlah petugas terbatas maka para narapidana perlu diajarkan bagaimana cara meningkatkan kemampuannya dalam mengelola stress untuk dapat menurunkan stres yang mereka alami sehingga mereka dapat hidup lebih nyaman selama menjalani hukuman penjara. Manajemen stres adalah suatu program untuk melakukan pengontrolan atau pengaturan stres yang bertujuan mengenal penyebab stres dan mengetahui teknik-teknik mengelola stres sehingga orang lebih baik dalam menguasai stres dalam kehidupannya daripada dihimpit oleh stres itu sendiri (Schafer, 2000).

\section{METODE PELAKSANAAN}

Kegiatan pengabdian kepada masyarakat ini diikuti oleh 28 narapidana pria lapas kelas I Tanjung Gusta Medan dengan usia 21- 60 tahun dan tingkat pendidikan SD - SMA. Metode pelaksanaan kegiatan pengabdian kepada masyarakat ini adalah psikoedukasi. Kegiatan psikoedukasi secara umum terdiri dari pretest, ceramah, tanya jawab, praktik, dan posttest. Kegiatan ini diikuti oleh 28 orang narapidana pria Lapas kelas I Tanjung Gusta Medan. Kegiatan terdiri dari 2 pertemuan tatap muka yang dilaksanakan pada tanggal 22 Oktober 2019 dan tanggal 26 Oktober 2019. Adapun detil kegiatan pelatihan dapat dilihat dalam uraian sebagai berikut :

1. Pertemuan 1, 22 Oktober 2019

Kegiatan diawali dengan perkenalan antara tim dengan para narapidana dan juga dengan sesama para narapidana agar keakraban terbangun dengan baik dan peserta merasa nyaman dalam mengikuti Pelatihan Manajemen Stres. Selanjutnya dijelaskan tujuan dan prosedur pelatihan dan dilakukan pretest untuk mengetahui tingkat stres peserta sebelum materi pelatihan diberikan.melalui pemberian skala Perceived Stress Scale (PSS). Selanjutnya dilakukan kegiatan ice breaking untuk menciptakan suasana yang menyenangkan dan membangkitkan semangat peserta untuk mengikuti materi pelatihan. Materi pelatihan diberikan dalam bentuk ceramah yang menjelaskan mengenai stres, stressor, dan manajemen stres. Dalam pelatihan peserta juga diminta memperagakan teknik-teknik manajemen stress seperti deep breathing. Di akhir sesi, peserta diminta menerapkan teknik-teknik manajemen stres yang sudah dipelajari untuk diterapkan secara mandiri selama 3 hari dalam kehidupan sehari-hari di lapas. 


\begin{tabular}{|c|c|c|c|}
\hline No & Waktu & Aktivitas & Tujuan \\
\hline 1 & $09.00-09.10$ & Membangun rapport & $\begin{array}{l}\text { Untuk membangun hubungan akrab dan suasana } \\
\text { intervensi kelompok yang menyenangkan sehingga } \\
\text { peserta dapat merasa nyaman dalam mengikuti } \\
\text { pelatihan Manajemen Stres }\end{array}$ \\
\hline 2 & $\begin{array}{l}09.100- \\
09.15\end{array}$ & $\begin{array}{l}\text { Menjelaskan tujuan } \\
\text { dan prosedur } \\
\text { intervensi }\end{array}$ & $\begin{array}{l}\text { Peserta memahami tujuan dan prosedur Pelatihan } \\
\text { Manajemen Stres }\end{array}$ \\
\hline 3 & $09.15-09.30$ & Pre-test & $\begin{array}{l}\text { Mengetahui tingkat stres peserta sebelum } \\
\text { mendapat pelatihan Manajemen Stres melalui } \\
\text { pemberian skala Perceived Stress Scale (PSS) }\end{array}$ \\
\hline 4 & $09.30-10.00$ & Ice Breaking & $\begin{array}{l}\text { Menciptakan suasana yang menyenangkan dan } \\
\text { membangkitkan semangat peserta untuk memulai } \\
\text { kegiatan intervensi }\end{array}$ \\
\hline 5 & $10.00-11.50$ & $\begin{array}{l}\text { Materi Stres dan } \\
\text { Manajemen Stres }\end{array}$ & Peserta memahami stres dan manajemen stres \\
\hline 6 & $11.50-12.00$ & $\begin{array}{l}\text { Tugas Penerapan } \\
\text { Manajemen Stres }\end{array}$ & $\begin{array}{l}\text { Peserta diberi tugas untuk menerapkan cara } \\
\text { mengelola stres yang sudah dipelajari dalam } \\
\text { kehidupan sehari-hari di lapas selama } 3 \text { hari secara } \\
\text { mandiri }\end{array}$ \\
\hline
\end{tabular}

Tabel 2.1. Jadwal Kegiatan Pertemuan 1, 22 Oktober 2019

2. Pertemuan 2, 26 Oktober 2019

Pertemuan kedua diawali dengan kegiatan ice breaking untuk membuat para peserta nyaman mengikuti kegiatan. Selanjutnya dilakukan review terhadap tugas penerapan teknik-teknik manajemen stres selama 3 hari. Dalam sesi ini peserta diberi kesempatan untuk mengungkapkan apa manfaat yang dirasakan dengan penerapan teknik-teknik manajemen stres yang sudah dipelajari dalam kehidupan sehari-hari dan apa saja hambatan yang ditemui dalam melakukannya.

\begin{tabular}{|c|c|c|c|}
\hline No & Waktu & Aktivitas & Tujuan \\
\hline 1 & $09.00-09.15$ & Ice breaking & $\begin{array}{l}\text { Menciptakan suasana yang } \\
\text { menyenangkan dan membangkitkan } \\
\text { semangat peserta untuk memulai } \\
\text { kegiatan intervensi }\end{array}$ \\
\hline 2 & $09.15-10.00$ & $\begin{array}{l}\text { Rexiewh } \\
\text { tugas }\end{array}$ & $\begin{array}{l}\text { Memeriksa pelaksanaan tugas untuk } \\
\text { mengetahui manfaat apa yang } \\
\text { dirasakan oleh peserta dari } \\
\text { penerapan teknik-teknik manajemen } \\
\text { stres yang telah dipelajari }\end{array}$ \\
\hline 3 & $10.00-10.15$ & Post test & $\begin{array}{l}\text { Mengetahui tingkat stres peserta } \\
\text { setelah mendapat pelatihan } \\
\text { Manajemen Stres melalui pemberian } \\
\text { skala Perceived Stress Scale (PSS) }\end{array}$ \\
\hline 4 & $10.15-10.30$ & Terminasi & $\begin{array}{l}\text { Mengakhiri intervensi dengan } \\
\text { menyampaikan kesimpulan hasil } \\
\text { intervensi kepada peserta }\end{array}$ \\
\hline
\end{tabular}

Tabel 2.2. Jadwal Kegiatan Pertemuan 2 


\section{HASIL}

Berdasarkan hasil pretest dan posttest yang dilakukan untuk mengukur tingkat stres peserta sebelum dan sesudah diberikan pelatihan Manajemen Stres dan dilaksanakan penerapan teknik manajemen stress selama 3 hari diperoleh gambaran bahwa terjadi penurunan tingkat stres pada peserta dimana jumlah peserta dengan tingkat stres tinggi sebelum diberikan pelatihan Manajemen Stres ada sebanyak $17,9 \%$ menurun menjadi $14,3 \%$, peserta dengan tingkat stres sedang sebelum diberikan pelatihan Manajemen Stres sebanyak $75 \%$ menurun menjadi 71,4 \%, dan peserta dengan tingkat stress rendah sebelum diberikan pelatihan Manajemen Stres sebanyak 7,1 \% meningkat menjadi $14,3 \%$.

\begin{tabular}{l|c|l}
\hline \multicolumn{1}{c|}{ TINGKAT STRES } & PRE-TEST & \multicolumn{1}{c}{ POST-TEST } \\
\hline Rendah & $7.1 \%$ & $14.3 \%$ \\
Sedang & $75 \%$ & $71.4 \%$ \\
Tinggi & $17.9 \%$ & $14.3 \%$ \\
\hline
\end{tabular}

Tabel 3.1. Gambaran Penurunan Tingkat Stres Narapidana Pria Kelas I Lapas Tanjung Gusta Medan Setelah Mengikuti Pelatihan Manajemen Stres

Dalam kegiatan review tugas yang dilakukan setelah penerapan teknik-teknik manajemen stres selama 3 hari dalam kehidupan sehari-hari di lapas beberapa peserta melaporkan bahwa penerapan teknik-teknik manajemen stres yang telah dipelajari membantu mereka dalam mengontrol emosi dan mengatasi sulit tidur. Namun beberapa peserta juga melaporkan bahwa mereka masih belum cukup terampil dalam menerapkan teknik-teknik yang dipelajari sehingga digunakan seingatnya saja. Penerapan secara rutin diharapkan dapat membuat para peserta memperoleh hasil yang maksimal dalam menurunkan tingkat stres mereka.

\section{KESIMPULAN}

Kesimpulan yang dapat diambil dari pelaksanaan kegiatan pengabdian kepada masyarakat ini adalah pelatihan manajemen stres dapat membantu para narapidana pria kelas I Tanjung Gusta Medan menurunkan tingkat stres.

1.1 Saran

Perlu dilakukan penyegaran secara berkala bagi para narapidana agar teknik-teknik manajemen stres yang sudah dipelajari tetap diterapkan dalam kehidupan sehari-hari di lapas. Selain itu, subyek yang sudah terampil dapat diminta untuk mengajarkannya kepada narapidana lainnya yang tidak ikut menjadi peserta dalam kegiatan pelatihan.

\section{UCAPAN TERIMAKASIH}

Tim pelaksana kegiatan pengabdian kepada masyarakat mengucapkan terima kasih kepada Lembaga Pengabdian Kepada Masyarakat USU yang telah mendanai kegiatan ini.

\section{DAFTAR PUSTAKA}

Akhmad, H. (2018, Des 27). Menkumham Sebut Lapas di Indonesia Over Kapasitas.

Cohen, S., Kamarck, T., Mermelstein, R.(1983). A Global Measure of Perceived Stress. Journal of Health and Social Behavior, 24, 386-396.

Gullone, E., Jones, T., \& Cummins, R. (2000). Coping Style and Prison Experience as Predictors of Psychological Well-Being in Male Prisoners. Psychiatry Psychol Law 7 
(2):171-181.

Mulyadi, L. (2005). Pengadilan Anak di Indonesia : Teori, Praktik, dan Permasalahannya. Bandung : Mandar Maju.

Sarafino, E. P. (2011). Health Psychology: Biopsychosocial Interactions. New York:

Wiley. Schafer, W. (2000). Stress Management for Wellness. $4^{\text {th }}$ Edition. USA :

Wadsworth.

Taylor, S, E. (2015). Health Psychology. $10^{\text {th }}$ Edition. New York : McGrawHill Education. 